Lidelöw H. and Jansson G. (2017). "The Effect of Pre-Engineering on Design Management Methods". In: LC3 2017 Volume II - Proceedings of the 25th Annual Conference of the International Group for Lean Construction (IGLC), Walsh, K., Sacks, R., Brilakis, I. (eds.), Heraklion, Greece, pp. 523-530. DOI: https://doi.org/10.24928/2017/0107

\title{
THE EFFECT OF PRE-ENGINEERING ON DESIGN MANAGEMENT METHODS
}

\author{
Helena Lidelöw ${ }^{1}$ and Gustav Jansson ${ }^{2}$
}

\begin{abstract}
Several methods exist for design management such as Agile project management, the Last Planner System ${ }^{\circledR}$, and configuration in diverse variants. Construction can be realized using different degrees of pre-engineering i.e. different production strategies, which can affect the design management method.

The research aim is to describe different design management methods and discuss their capacity to function in existing production strategies in construction. Data was collected as secondary data from earlier publications on Agile project management, the Last Planner \& system, configuration, and visual planning.

Agile project management has a strong focus on customer value and lends itself well to situations with little pre-engineering. The Last Planner System ${ }^{\circledR}$ in design has a strong focus on the co-creation of flow and coordination of actions. In industrialised housing a dialect of Last Planner System ${ }^{\circledR}$ named KI-VP is implemented drawing upon predefinition of design tasks through standardized work. Configuration is the ultimate predefined design stage, where everything can be automated based on product variants.
\end{abstract}

Keywords: Agile, Last Planner System ${ }^{\circledR}$, Production strategies, Visual planning.

\section{INTRODUCTION}

The design phase is characterized by uncertainty, iterative, and specialized work. Standardization and pre-engineering is argued to decrease the amount of design work. Within the Lean Construction community, several design management methods have been studied such as Agile project management (e.g. Demir and Theis 2016) and Last Planner ( ${ }^{\circledR}$ in design (e.g. Fosse and Ballard 2016). When using standardized products (e.g. a singlefamily home with product variants), the design phase is repetitive and takes the form of a configuration of pre-set alternatives preceded by a product development phase (e.g. Wikner and Noroozi 2016).

Construction can be realized through different production strategies, ranging from no pre-engineering up to fully standardized products, figure 1, (Johnsson 2013). In the situation of designing e.g. a concert hall, the level of pre-engineering is often low or zero, which means designers work directly with codes as their base going from a conceptual to a fully detailed design without the involvement of prefab suppliers, upper row in figure 1. The most common situation is row 2 e.g. the design of a multi-family building, where designers draw upon the knowledge from suppliers combining existing parts as beams, floor systems, windows etc. into a design. Row 4 captures another common situation; the standard products of e.g. prefabricated single-family homes where the design is completed

1 Associate Professor, Division of Industrialized and Sustainable Construction, Department of Civil, Environmental, and Natural Resource Engineering, Luleå University of Technology, Luleå, Sweden, helena.lidelow@ltu.se

2 Assistant Lecturer, Division of Industrialized and Sustainable Construction, Department of Civil, Environmental, and Natural Resource Engineering, Luleå University of Technology, Luleå, Sweden, gustav.jansson@ltu.se 
before the customer enters the process. The customer's task is to choose from predefined variants and the design process is a pure configuration. Row 3 describes a situation in between the combination of existing parts and a selection of variants, where configuration is combined with traditional design.

The aim of this research is to describe different design management methods and discuss their capacity to function in the production strategies in figure 1 i.e. in situations with varying levels of pre-engineering. The purpose is not to advocate any design management method as superior to another, but rather to contextualize them and provide reasons for choosing between methods. The viewpoint is that the design phase is part of the production information flow (Winch 2003) momentarily setting aside design as a learning process (Kalsaas 2011).

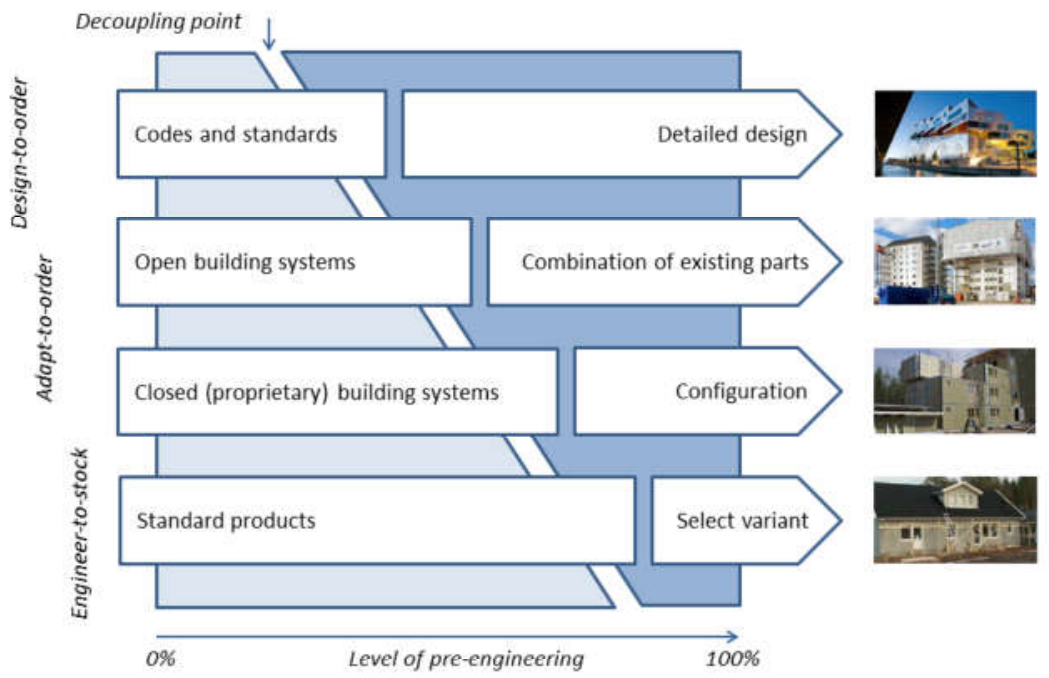

Figure 1: Different types of engineer-to-order production strategies in construction, examples from housing (Johnsson 2013)

\section{METHOD}

A literature study based on publications from IGLC was the onset to explain different design management methods in construction. This decision was made based on the first author's preunderstanding that IGLC is an arena where design management in construction has been vividly discussed over the years. Two major methods have been the discourse: Agile Project Management and Last Planner ${ }^{\circledR}$ in design. A search for Last Planner within IGLC yields 224 results, which is narrowed down to 25 papers that includes "design" as a keyword, whereof 10 are case studies. Looking into Agile Project Management on IGLC reveals 24 research papers containing 4 studies in design.

Looking into the design of prefabrication, 6 papers emerge. Configuration in design reveals 4 papers. The low number of publications concerning construction design with a high degree of prefabrication motivated an additional search in other search engines.

The results from literature helps to build a basic understanding of different design management methods. Their ability to handle uncertainty, iterations, and specialized work is discussed as well as the standpoint of the method concerning conversion, flow or value (Ballard and Koskela 1998). The intention of the design management methods is contrasted with the situations in figure 1 . The result is presented in figure 5 and each row in the diagram discussed and explained. 


\section{Design MANAGEMENT METHOdS}

\subsection{Agile Project Management}

Agile project management is a software product development method suitable for situations where the requirements are partly unknown and needs to be developed during the design process, (Beck et al. 2001). While Lean focuses on efficiency and requires stability, the agile process focuses effectiveness (Naim and Barlow, 2003). Ballard and Koskela (1998) captured this through presenting design management as being captured as one of three views: the conversion of inputs to outputs, the flow of information, or the creation of customer value. The basic values and principles in agile project management is to prioritise interaction, functional solutions, cooperation with the client, and response to change as opposed to following a pre-set plan and a contract (Beck et al. 2001):

- The client representative is part of the project team, acts as the product owner

- After setting the vision, work is subdivided in cycles of 4-8 weeks - $\underline{\text { sprints }}$

- At the beginning of the sprint, the product owner and the project team decides what client needs should be addressed and solved during the coming sprint. The client needs are often expressed as user stories and collected in a product backlog

- When the sprint ends, deliverables are presented to and tested by the product owner.

- New user stories are prioritised and the cycle starts over again.

During the sprint, the project team is ideally co-localized and meets at daily scrums managed by a scrum master. The daily scrum, which is a short daily check-up meeting, takes place in front of a scrum board, figure 2 .

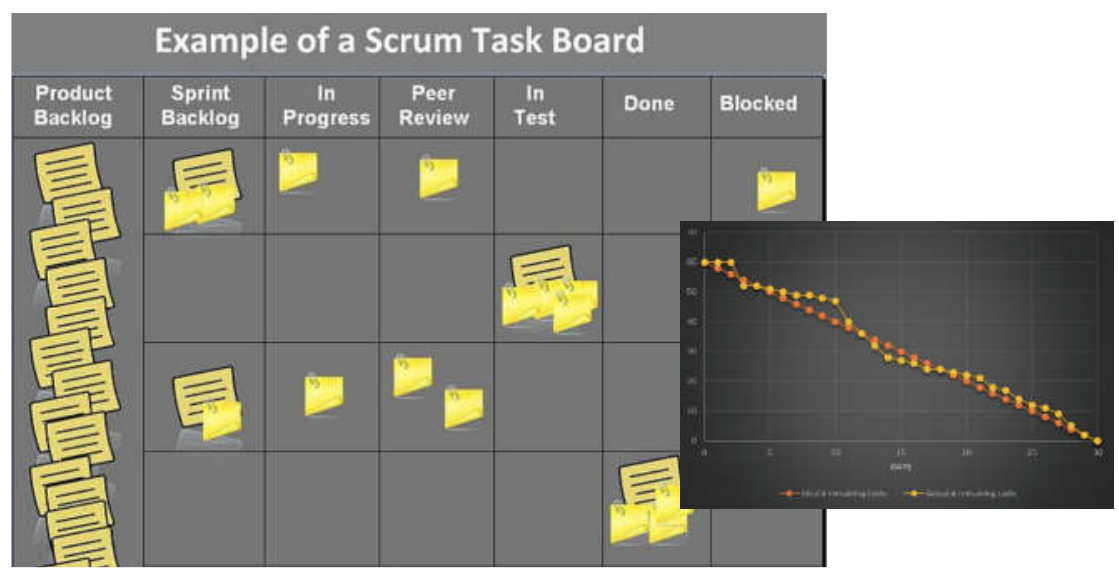

Figure 2: Scrum board (by Dr Ian Mitchell, 2016) with burn-down chart

The scrum board visualizes the product backlog, the vision, a burn-down chart, and work tasks deducted from the user stories. Every day, work task status is updated and new work tasks distributed within the team. Agile methods have no intention of finding an optimal sequence of design tasks, as opposed to Lean methods (Koskela et al 1997).

The logic in Agile project management is to temporarily freeze the uncertainty of changing requirements by asking the product owner to prioritise what user stories and requirements in the product backlog to focus on during the sprint. By asking the project owner to prioritise, customer value is ensured (Owen et al, 2006). Another priority is to 
keep time and resources fixed while continuously revaluing the project goals (ibid). They further suggest that Agile should be applicable in projects where complexity and variation is substantial, where solutions to requirements evolve or are likely to change during the project, and where a considerable amount of clients are involved creating constant negotiation of trade-offs.

Demir and Theis (2016) developed Agile Design Management to adjust Agile project management to the construction design phase. This was made by clarifying who the product owner is, on what level he/she enters the process, and by adding a hierarchical structure for decision making, planning, and actual work. The VPO Lean design management model presented by Emmitt et al. (2004) resembles Agile with workshops targeted at value creation, but emphasises the connection between value, process, and operations.

\subsection{Last Planner (ㄹ in Design}

Last Planner ® (Ballard, 2000) has been successfully implemented and used for construction, also in the design phase (Miles, 1998). The core of the Last Planner ${ }^{\circledR}$ system is to plan, lookahead, follow-up, and counteract problems beforehand to create a proactive work mode.

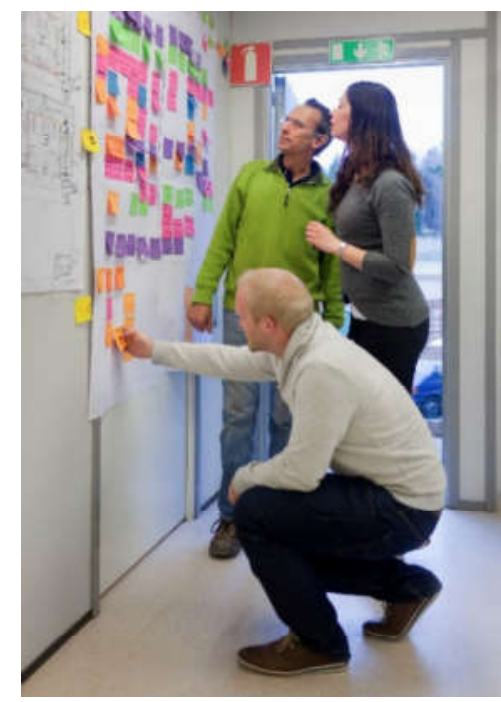

Figure 3: Pull-planning session at NCC Construction, Sweden (NCC, 2016)

Fosse and Ballard (2015) summarized the Last Planner ${ }^{\circledR}$ system:

- Planning: Pull-planning sessions involve relevant project participants to create a plan based on needs across the team. Ownership of the plan is strengthened among participants as people can better explain and solve task sequencing of complex problems with visual post-it plans. This increases transparency of how design work must fit within the available time given by the plans for construction.

- Lookahead: In contrast to traditional planning, where problems are solved after they arise, one of the strengths of LPS is always focusing on making tasks ready in the coming weeks and solving problems proactively. 
- Checking: Tracking PPC (percent part complete) and root causes for failed commitments provides information on how work actually is performed compared to how it was planned.

- Learning: Analysis of PPC and root cause analysis over time provides useful insight into plan reliability trends so that one can implement counter-measures for problems that systematically cause failure to complete tasks as planned.

In the beginning of the design phase, time is spent on capturing the client requirements as these govern what activities must take place during design. The team is not collocated, but pull-planning sessions are done with all the members of the design team present. Fundli and Drevland (2014) presented a variant of LPS in design where collocation was integrated in it drawing inspiration from integrated concurrent engineering. The pull-planning session results in a visual plan with post-its, figure 3. Meetings using the Last Planner ${ }^{\circledR}$ system is not prescribed as daily meetings in front of the board, but rather re-planning sessions on a weekly basis. In between, the plan is frozen. Each actor can only move their own post-its on the plan.

Last Planner ${ }^{\circledR}$ in design was extended by Kalsaas et al. (2016) through merging ideas from Agile and Last Planner ( ${ }^{\circledR}$ primarily to support increased learning in the design process. Instantask is a visual communication support with an agile approach to enhance Last Planner by adding new questions to the decision flow in look-ahead planning (Daou et al. 2015). There are also tools to support the use of Kanban cards with BIM (KanBIM from Sacks et al 2011) and VisiLean developed by Dave et al (2013).

\subsection{Design Management with Predefinition of Design Tasks}

The Knowledge Innovation Visual Planning (KI-VP) method is based on design activities broken down into manageable tasks (Tanaka 2002). To increase design performance, predefinition of reoccurring tasks helps reduce variability, increase efficiency, minimize errors, capture, and manage knowledge. Predefinition functions as a base for continuous improvements and learning (Hoppmann et al. 2011). Being a part of Lean Product Development Flow (LPDF), the KI-VP method contains tasks that are predefined specifying what, who, when, and how the task should be operated in the design phase. Oppenheim (2004) describes that planning of the product development flow takes place in a dedicated room with magnetic planning boards where activities are mapped showing the current state of the development work. Compared to Lookahead planning in LPS, the KIVP method contains daily meetings for fast feedback and visualisation of deviations from the takt time of the overall design plan. According to Reinertsen (2009), the management of queues in LPDF is central for balancing capacity utilisation. Queues of work tasks in product design are invisible without activity lists. Design queue inventories can quickly grow as a result of several concurrent deliveries, delayed response time, or from pauses and iterations in design work. Maximising the capacity of resources, increases the queues in design exponentially, which leads to longer cycle times, costs for delay, motivation problems, and lower quality (Reinertsen 2009). Flow efficiency is focused through visualizing daily work task queues and prioritise resources to queueing activities instead of matching work tasks to available resources.

The KI-VP concept is implemented in the design processes of industrialised housebuilders to minimize throughput time, plan for takt time, hold meetings that minimize waste, and continuously improve design tasks (Jansson et al. 2016). Standard operation sheets (SOS) supporting the design tasks specify how predefined solutions and process snippets are applied in the specific construction project. In daily meetings, communication 
problems, pauses or unsolved design tasks are visualised. The KI-VP plan contains a two week Lookahead plan with specified work tasks per day and a 28 weeks predefined midterm plan with specified work tasks per week. Project specific tasks can amend the plan.

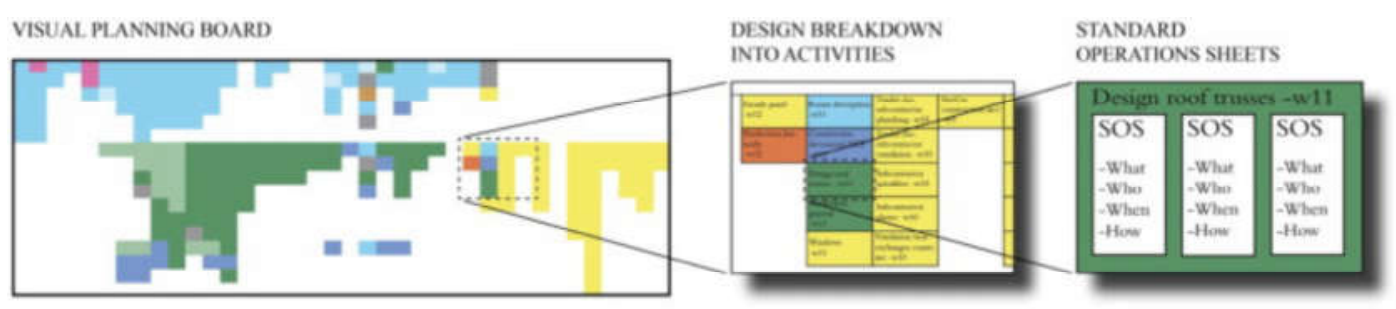

Figure 4: KI-VP board, activities and tasks with standard operation sheets.

\subsection{Configuration Management in Design}

When using configuration of products all design activities are executed before the client enters the process. With a high pre-engineering of the product offer, a short distance between sales and production contexts could result in benefits, but also drawbacks for the entire flow. This puts pressure on the management to schedule and coordinate orders after the decoupling point (Hines et al. 2004), figure 1. Pre-engineering contexts face the challenge of balancing the input rate of orders with the variety of product configurations. A combination of customer enquiry management (CEM) and order release management was described by Thurer et al. (2014) smoothing out peaks and troughs for a stable process of configuration before production. The planning of product configuration after the decoupling point is managed as part of the production flow (Wikner and Noroozi 2016). Further, the configuration execution is planned and controlled as production work (ibid). Visualisation methods for planning configuration of products are focused on the preengineering work instead of the execution i.e. there are no visual supports for the configuration process itself.

\section{Linking Design Management to PRE-EngineERING}

Agile project management is suitable in projects where there are uncertainties not only pertaining to the solution, but also concerning what the actual requirements are. Therefore, it should lend itself perfectly to larger design projects with a unique character. The iterative nature of agile project management includes the client and supports problem seeking and value creation during the design process. Value creation has a higher priority than flow. Agile project management has little to do with conversion of inputs to outputs. Further, the notion of collocation of the team as a recommended ingredient in agile project management points to the fact that the method works best in complex, large projects where the team can be collocated for a substantial amount of time.

Last Planner ${ }^{\circledR}$ is also useful in large projects where communication and coordination between many specializations are needed. However, Last Planner ${ }^{\circledR}$ does not include the client as a default member of the project team and therefore, the requirement set should be well defined during the start-up of the design phase. Last Planner ${ }^{\circledR}$ allows collocated teams but does not require it. This is a valuable quality in construction design as it is performed by many different firms in collaboration. LPS in design focuses the creation of flow with the underlying intent to create value.

In the specific situation of having a design process where large parts of the solution is already known i.e. in industrialised construction, there is a possibility to pre-engineer 
snippets of the design process as well. This is captured by the KI-VP method, where the post-it boards used in Agile project management and Last Planner ${ }^{\circledR}$ are replaced by preprinted, predefined design process snippets. The order of execution is also predefined. This leads to a higher degree of predictability with the possibility to support tasks with standard operation sheets. However, KI-VP is not a method suitable when client requirements are not known or many new actors enter the design process - in those cases the power of predefinition is lost. The focus of the method lies in converting inputs to outputs and creating flow, while value creation is an underlying intention.

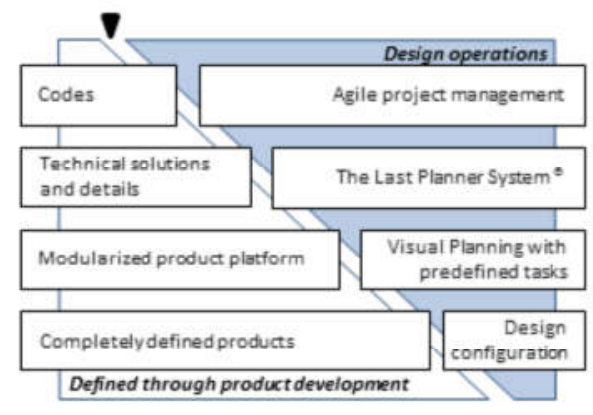

Figure 5: Visual planning methods in design in relation to pre-engineering

Configuration in design requires a fully known design solution and is thus only useful in cases where the final product is completely pre-engineered. A configuration process automates the design flow and focuses entirely on converting inputs to outputs. Value creation is ensured in the preceding product development phase.

All of the presented visual planning methods have merits in different situations and also support different underlying Lean strategies. Agile project management contains a strong focus on creating customer value, while Last Planner ${ }^{\circledR}$ contributes with common goal setting and letting everyone see and construct the flow. Between Last Planner ${ }^{\circledR}$ and Agile there have been several attempts to combine their strengths (e.g. Kalsaas et al. 2016). $\mathrm{KI}-\mathrm{VP}$ is flow-oriented with predefined process flow and supports standard operations. Configuration is a fully automated, fast design flow, but the creation of customer value is pre-set and cannot change between projects - it must be made through product development.

\section{REFERENCES}

Ballard, G. (2000). The Last Planner System of Production Control. PhD thesis, University of Birmingham.

Ballard, G. and Koskela, L. (1998). On the Agenda of Design Management Research. In proceedings from IGLC-6, Guarujá, Brazil, July 1998.

Beck, K. et al. (2001). Manifesto for Agile Software Development, http://Agilemanifesto.org, 2016-12-11.

Daou, E., Gharzouzi, P., Sreih, E., and Hamzeh, F. (2015). Instantask: Designing a Visual Application for Enabling Agile Planning Response. In proceedings from IGLC-23, Perth, Australia, July 2015.

Dave, B., Boddy, S., and Koskela, L. (2011). Visilean: Designing a Production Management System with Lean and BIM. In proceedings from IGLC-19, Lima, Peru, July 2011. 
Demir, S.T. and Theis, P. (2016). Agile Design Management - The Application of Scrum in the Design Phase of Construction Projects. In proceedings from IGLC-24, Boston, USA, July 2016.

Emmitt, S. , Sander, D. and Christoffersen, A.K. (2004). Implementing Value Through Lean Design Management. In proceedings from IGLC-12, Helsingør, Denmark, Aug 2004.

Fosse, R. and Ballard, G. (2016). Lean Design Management in Practice with the Last Planner System. In proceedings from IGLC-24, Boston, USA, July 2016.

Fundli, I.S. and Drevland, F. (2014). Collaborative Design Management - A Case Study. In proceedings from IGLC-22, Oslo, Norway, June 2014.

Hines, P., M. Holweg, N. Rich. (2004). Learning to evolve: A review of contemporary lean thinking. Inter. J. Oper. Prod. Manag. 24(10): 994-1011.

Hoppmann, J., Rebentisch, E., Dombrowski, U., and Zahn, T. (2011). A Framework for Organizing Lean Product Development. Eng. Management Journal, 23:1, 3-15.

Jansson, G., Viklund, E. and Lidelöw H. (2016). Design Management using Knowledge Innovation and Visual Planning. Automation in Construction 72(3):330-337.

Johnsson, H. (2013). Production Strategies for Pre-Engineering in House-Building: Exploring Product Development Platforms. Construction Management and Economics 31(9):941-958.

Kalsaas, B. T. (2011). The Last Planner System Style of Planning: Its Basis in Learning Theory. Journal of Engineering, Project and Production Management, 2(2), pp.88-100.

Kalsaas, B.T., Bonnier, K.E. and Ose, A.O. (2016). Towards a Model for Planning and Controlling ETO Design Projects. In proceedings from IGLC-24, Boston, USA, July 2016

Koskela, L., Ballard, G., and Tanhuanpää, V.-P. (1997). Towards Lean Design Management. In proceedings from the IGLC-5, Gold Coast, Australia, July 1997.

Miles, R.S. (1998). Alliance Lean Design/Construct on a Small High Tech Project. In proceedings from IGLC-6, Guarujá, Brazil, July 1998.

Naim, M.M. and Barlow, J. (2003). An Innovative Supply Chain Strategy for Customized Housing. Construction Management and Economics 21(6):593-602.

Owen, R., Koskela, L., Henrich, G., and Codinhoto, R. (2006). Is Agile Project Management Applicable to Construction? In proceedings from IGLC-14, Santiago, Chile, July 2006.

Reinertsen, D.G. (2009). The Principles of Product Development Flow: Second Generation Lean Product Development. Celeritas Publishing, pp 304.

Sacks, R., Barak, R., Belaciano, B., Gurevich, U., and Pikas, E. (2011). Field Tests of the KanbimTM Production Management System. In proceedings from IGLC-19, Lima, Peru, July 2010.

Tanaka, T. (2002). Efficient Creativity: JIT for Knowledge-Workers. In proceedings from JMAC Consiel SpA, Milan, 2002.

Thurer, M., Stevenson, M., Silva, C., Land, M.J., Fredendall, L.D., Melnyk, S.A. (2013) Lean Control for Make-to-Order Companies: Integrating Customer Enquiry Management and Order Release, 23:3, 463-476.

Wikner, J. and Noroozi, S. (2016). A Modularised Typology for Flow Design based in Decoupling Points - a Holistic View on Process Industries and Discrete Manufacturing Industries. Production Planning \& Control, 27(16):1344-1355.

Winch, G. (2003) Models of manufacturing and the construction process: the genesis of re-engineering construction. Building Research \& Information, 31(2), 107-18. 